\title{
Entrepreneurship and Innovation
}

\section{Sponsored by SCRA}

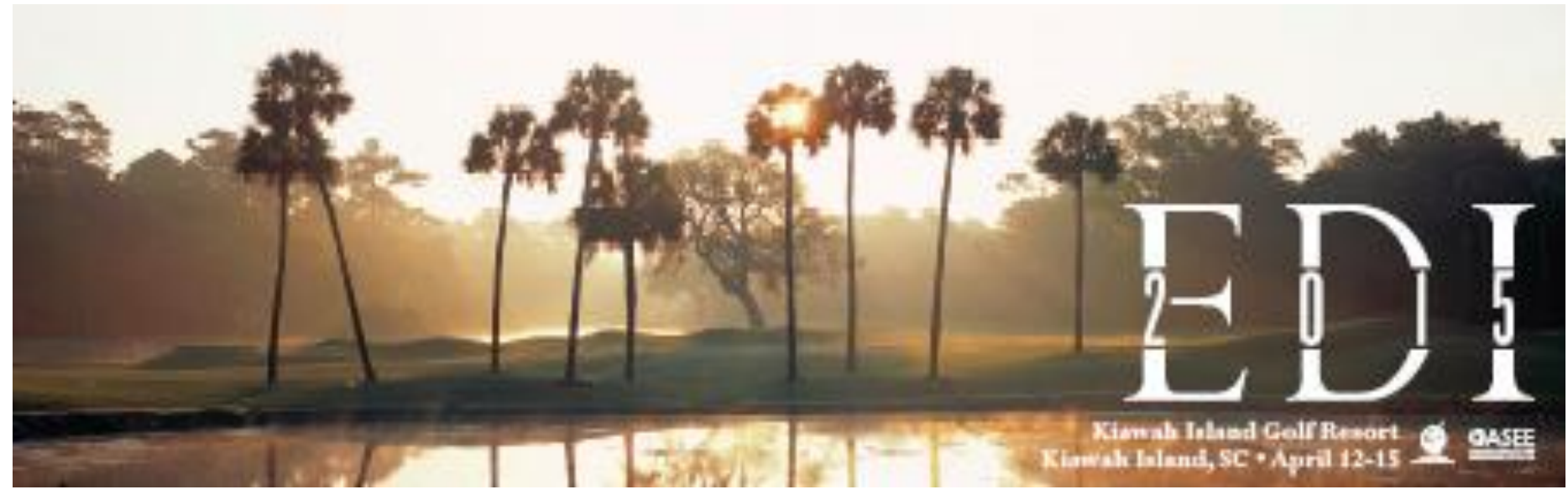

\section{Lead Organizers:}

Tom Byers, Stanford University Rich Brown, University of Utah 


\section{EDI 2015 Themes}

$\checkmark$ The NAE's Grand Challenges Scholars Program, which has five components: research experience, interdisciplinary curriculum, entrepreneurship, global dimension, and service learning.

$\checkmark$ Improving diversity, including strategies for recruitment, retention, mentoring, and graduation. 


\section{Agenda}

A. Venture Creation

- Rich Brown (Dean, University of Utah) and Paul Slusser (Utah alum and co-founder, Power Practical, Inc.)

- Phil Weilerstein (CEO, VentureWell) and Riley Cernica (I-Corp alum, Clemson)

B. Inclusion and Diversity

- Kathy Banks (Dean, Texas A\&M)

- Melinda McClure (Senior and President, Student Engineering Council, Texas A\&M)

C. Student and Faculty Engagement

- John DesJardins (Professor of Bioengineering, Clemson)

- Brie Przestrzelski (Ph.D. candidate and University Innovation Fellow, Clemson)

D. Table Discussion of 3 Topics and Sharing of Summaries 
Table Discussions and Highlights ... 


\section{A. Commercialization and Venture Formation}

What, if any, incentives or support should universities provide to encourage entrepreneurship and venture formation among their faculty and students? Should disclosures, patents, startups, or successful commercialization efforts be considered in promotion and tenure decisions? Should universities invest directly in spin-out companies?

\section{B. Inclusion and Diversity}

How does a lack of diversity affect the ability to innovate? In what ways should diversity and inclusion be included as a component to strengthen and improve our educational programs? How can we use innovation and entrepreneurship to appeal to underrepresented students and increase participation?

\section{Student and Faculty Engagement}

Is your institution better suited for a bottom-up (student-led) or top-down (administrative) approach to changing the innovation and entrepreneurship ecosystem? How can your college best leverage student and faculty partnerships and leadership to create lasting institutional change? 


\section{Thank You!}

\section{Rich \& Paul, Phil and Riley, \\ Kathy \& Melinda, John \& Bre}

\section{Anand and Tom K.}

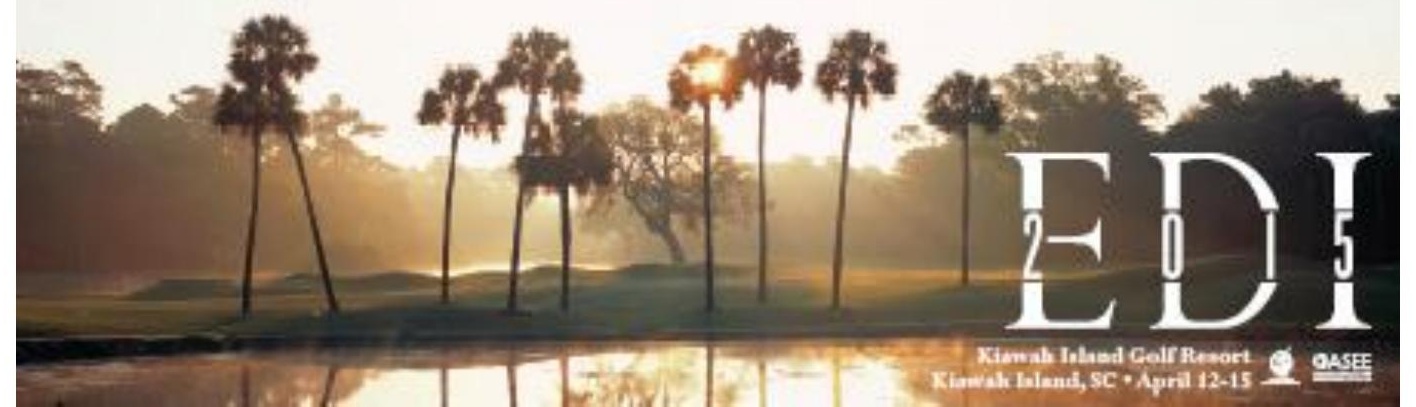

